\title{
PERMINTAAN KONSUMEN JASA LINGKUNGAN WISATA ALAM MEMPAWAH MANGROVE PARK (MMP) KABUPATEN MEMPAWAH
}

\author{
(Consumer Demand For Natural Tourism Environment Services In Mempawah Manggrove \\ Park (MMP) Mempawah District)
}

\author{
Sri Rahayuni, Emi Roslinda, Sudirman Muin \\ Fakultas Kehutanan Universitas Tanjungpura Pontianak. J1. Daya Nasional Pontianak 78124 \\ Email: Srirahayunifahut156@gmail.com
}

\begin{abstract}
Mempawah Mangrove Park (MMP) is an ecotourism in West Kalimantan, especially in Mempawah Regency. MMP besides a tourist attraction is also an area of research and education. Visitors tend to increase every year starting from August 232016 - April 272017 visitors come from local communities of Mempawah Regency and from outside Mempawah Regency such as Pontianak City, Singkawang City and Kubu Raya. Factors that influence the demand for MMP Mangrove nature tourism consumers are attractiveness, travel costs, time, and income. The research aims to measure the demand of consumers of Mempawah District MMP natural tourism services, and examine the factors that influence the demand for consumers of MMP natural tourism services. The sample used in this study were 45 respondents who visited MMP using the Accidental Sampling method. The analytical method in this study is descriptive analysis, basic assumption test, classic test, and multiple linear analysis. Descriptive analysis result of the demand consumers of MMP natural tourism services indicate that consumer demand is said to be high. The results of 45 respondents in this study were 22 respondents (48.89\%) visited 3 times in the last 1 year. The results of the study used the basic assumption test, classic assumption test and multiple linear regression. The results of multiple linear regression analysis show that attraction variables have a positive and significant effect on the demand of consumers of MMP natural tourism services. Travel and time cost variables show a negative and insignificant influence on the demand of consumers of MMP natural tourism services because most of the visitors are local people of Mempawah Regency who do not require a high enough travel cost and a long time. The income variable shows a negative and significant effect on the demand of consumers of MMP natural tourism services. This happens to income still in the low category because most MMP visitors are status young as students who do not have a steady income.
\end{abstract}

Keywords: Attractiveness, Consumer Demand, Income, MMP, Time and Travel Cost.

\section{PENDAHULUAN}

Wisata alam (ekowisata) adalah suatu bentuk kegiatan pariwisata yang memanfaatkan keaslian lingkungan alam, dimana terjadi interaksi antara lingkungan alam dan aktivitas rekreasi, konservasi dan pengembangan, serta antara penduduk dan wisatawan. Berdasarkan definisi tersebut dapat dikatakan bahwa kegiatan ekowisata mengintegrasikan kegiatan pariwisata, konservasi dan pemberdayaan masyarakat lokal, sehingga masyarakat setempat dapat ikut serta menikmati keuntungan kegiatan wisata tersebut melalui pengembangan potensi-potensi lokal yang dimiliki (Suzana, et al, 2011).

Kawasan hutan mangrove di Kabupaten Mempawah Kalimantan Barat merupakan kawasan pelestarian alam yang oleh masyarakat terutama dimanfaatkan untuk pariwisata dan rekreasi alam. Permintaan pariwisata adalah jumlah total 
dari orang yang melakukan perjalanan untuk menggunakan fasilitas dan pelayanan wisata di tempat yang jauh dari tempat tinggal dan tempat kerja (Indra, 2009). Berdasarkan informasi dari pihak pengelola wisata alam Mempawah Mangrove Park (MMP) jumlah pengunjung mengalami peningkatan dan berdasarkan data yang diperoleh dari pihak pengelola bahwa sejak diresmikan objek wisata alam MMP bulan Agustus 2017 sampai 30 April 2017 tercatat jumlah pengunjung wisata alam MMP berjumlah 124.249 orang. Seiring dengan meningkatnya potensi daya tarik suatu objek wisata menyebabkan akan meningkatnya permintaan konsumen untuk berwisata ke objek wisata alam tersebut. Menurut Ariyanto (2005), faktor-faktor yang menentukan permintaan terhadap daerah kunjungan wisata antara lain ; (1) harga (price), (2) daya tarik wisata (tourist attractions), (3) fasilitas yang tersedia (tourist facilities), (4) bentuk-bentuk pelayanan lainnya (services) seperti transportasi lokal, telekomunikasi, dan hiburan, (5) kemudahan-kemudahan untuk berkunjung (accessibilities) seperti sarana jalan, jembatan, tenaga listrik, atau persediaan air bersih, (6) kenyamanan dan keamanan.

Masalah penelitian ini bagaimana permintaan konsumen jasa lingkungan wisata alam MMP Kabupaten Mempawah, dan faktor-faktor apa saja yang mempengaruhi permintaan konsumen jasa lingkungan wisata alam MMP Kabupaten Mempawah. Tujuan penelitian ini adalah mengukur permintaan konsumen jasa lingkungan wisata alam MMP Kabupaten
Mempawah, dan mengkaji faktor-faktor yang mempengaruhi permintaan konsumen jasa lingkungan wisata alam MMP Kabupaten Mempawah.

\section{METODE PENELITIAN}

Penelitian dilaksanakan di Obyek wisata MMP di Desa Pasir Kecamatan Mempawah Hilir Kabupaten Mempawah selama \pm 4 minggu di lapangan. Alat dan bahan yang digunakan antara lain peta lokasi, digunakan sebagai alat bantu untuk menunjukan letak lokasi penelitian, kuisioner. Penelitian ini menggunakan 5 (lima) variabel yang terdiri atas 1 (satu) variabel terikat dan 4 (empat) variabel bebas. Variabel tersebut meliputi, Variabel terikat dalam penelitian ini adalah permintaan konsumen jasa lingkungan wisata alam MMP (Y). Variabel bebas yaitu daya tarik objek wisata alam MMP $\left(\mathrm{X}_{1}\right)$,variabel ini diukur menggunakan skala Likert, biaya perjalanan ke rekreasi wisata MMP $\left(\mathrm{X}_{2}\right)$, waktu perjalanan $\left(\mathrm{X}_{3}\right)$, pendapatan individu $\left(\mathrm{X}_{4}\right)$.

Permintaan konsumen terhadap jasa lingkungan wisata alam MMP maka diambil sampel penelitian yang berasal dari pengunjung (wisatawan) wisata alam MMP dan dilakukan dengan metode Accidental Sampling. Pengaruh variabel bebas (Xi) terhadap variabel terikat (Y) digunakan yaitu regresi berganda yang ditransformasi ke dalam bentuk Log natural (ln) dengan pendekatan OLS (Ordinary Least Squares), sehingga terbentuk persamaan regresi linear berganda yang dapat diekspresikan dalam bentuk persamaan yang menghubungkan variabel terikat $(\ln \mathrm{Y})$ dengan variabel bebas $\left(\ln \mathrm{X}_{\mathrm{i}}\right)$ berikut: 
1. $\ln X_{1}=$ Daya tarik wisata alam MMP

2. $\ln \mathrm{X}_{2}=$ Biaya perjalanan (travel cost method)

3. $\ln \mathrm{X}_{3}=$ Waktu perjalanan ke wisata alam MMP

4. $\ln \mathrm{X}_{4}=$ pendapatan $/$ penghasilan responden perbulan

Analisis regresi berganda memerlukan beberapa asumsi (asumsi dasar dan asumsi klasik) agar model tersebut layak dipergunakan. Asumsi dasar yaitu uji normalitas data dengan menggunakan skewness dan kurtosis. Asumsi klasik yaitu uji multikolinearitas, Gejala multikolinearitas dalam model regresi dapat dilihat dari nilai toleransi dan nilai VIF (Varian Inflation Factor) pada model

Tabel 1. Identitas Responden Berdasarkan Tingkat Pendidikan (Identity of Respondents by Education Level)

\begin{tabular}{llll}
\hline No & Pendidikan & $\begin{array}{l}\text { Jumlah Reponden } \\
\text { (Orang) }\end{array}$ & $\begin{array}{l}\text { Persentase } \\
(\mathbf{\%})\end{array}$ \\
\hline 1 & SD & 1 & 2.20 \\
2 & SMP & 11 & 24.40 \\
3 & SMA & 24 & 53.40 \\
4 & Peguruan Tinggi & 9 & 20.00 \\
\hline & Total & 45 & 100 \\
\hline
\end{tabular}

Sumber : Hasil analisis data primer 2018

Karakteristik responden MMP berdasarkan umur responden 14 - 24 tahun $(57,78 \%)$ seperti tabel 2.

Tabel 2. Identitas Responden Berdasarkan Kelompok Umur (Identity of Respondents by Age Group)

\begin{tabular}{llll}
\hline No & $\begin{array}{l}\text { Umur } \\
\text { (Tahun) }\end{array}$ & $\begin{array}{l}\text { Jumlah responden } \\
\text { (Orang) }\end{array}$ & $\begin{array}{l}\text { Persentase } \\
\text { (\%) }\end{array}$ \\
\hline 1 & $14-24$ & 26 & 57,78 \\
2 & $25-35$ & 11 & 24,44 \\
3 & $36-46$ & 8 & 17,78 \\
\hline & Jumlah & 45 & 100 \\
\hline
\end{tabular}

Sumber : Hasil analisis data primer 2018

Karakteristik responden MMP berdasarkan jenis kelamin (62,22 \%) mayoritas berjenis kelamin perempuan seperti tabel 3 . 
Tabel 3. Identitas Responden Berdasarkan Jenis Kelamin (Identity of Respondents by Gender)

\begin{tabular}{llll}
\hline No & Jenis Kelamin & $\begin{array}{l}\text { Jumlah responden } \\
\text { (Orang) }\end{array}$ & $\begin{array}{l}\text { Persentase } \\
(\mathbf{\%})\end{array}$ \\
\hline 1 & Laki-laki & 17 & 32,78 \\
2 & Perempuan & 28 & 62,22 \\
\hline & Jumlah & 45 & 100 \\
\hline
\end{tabular}

Sumber : Hasil analisis data primer 2018

Pendapatan responden kurang dari

yakni 53,4\% berasal dari masayarakat Rp 1. 700.000 (51.1 \%). Berdasarkan hasil wawancara di lapangan sebagaian besar pengunjung objek ekowisata MMP lokal yaitu Kabupaten Mempawah (kota Mempawah dan sekitarnya) seperti tabel 4.

Tabel 4. Daerah Asal Pengunjung Objek Wisata Alam MMP (Area Of Origin Of Visitors To MMP Natural Attractions)

\begin{tabular}{llll}
\hline No & Daerah Asal & Jumlah Responden & Persentase (\%) \\
\hline 1 & Lokal Kab. Mempawah & 24 & 53,4 \\
2 & Non lokal Kab. Mempawah & 21 & 46,6 \\
3 & Luar Kalimantan Barat & 0 & 00,0 \\
\hline
\end{tabular}

Sumber : Hasil analisa data primer, 2018

\section{B. Tingkat Permintaan Konsumen}

Hasil pengamatan permintaan konsumen wisata alam MMP dilihat pada tabel 5 .

\begin{tabular}{lllll} 
Tabel & $\begin{array}{l}\text { 5. } \\
\text { Karakteristik } \\
\text { Lingkungan } \\
\text { Based on Demand for Natural Tourism Consumer }\end{array}$ & $\begin{array}{l}\text { Responden } \\
\text { Wisata Alam }\end{array}$ & $\begin{array}{c}\text { Berdasarkan } \\
\text { PMP (Characteristics of Respondents }\end{array}$ \\
\hline No & Permintaan & $\begin{array}{l}\text { Frekuensi } \\
\text { (Orang) }\end{array}$ & $\begin{array}{l}\text { Persentase } \\
(\%)\end{array}$ & Keterangan \\
\hline 1 & Tinggi & 22 & 48,89 & $\geq 3 \mathrm{kali} / \mathrm{th}$ \\
2 & Sedang & 16 & 35,56 & $2 \mathrm{kali} / \mathrm{th}$ \\
3 & Rendah & 7 & 15.55 & $<2 \mathrm{kali} / \mathrm{th}$ \\
\hline & Total & 45 & 100 & \\
\hline
\end{tabular}

Sumber : Hasil analisa data primer, 2018

Berdasarkan hasil wawancara menunjukkan bahwa permintaan konsumen terhadap wisata alam MMP tergolong tinggi. Hal ini terlihat dari 45 responden sebanyak 22 responden $(48,89 \%)$ berkunjung sebanyak lebih dari 3 kali dalam setahun terakhir. Tingginya tingkat permintaan konsumen tersebut merupakan pengunjung

masyarakat lokal (Kabupaten Mempawah), sedangkan pengunjung dari luar Kabupaten Mempawah dengan tempat tinggal yang jauh dari objek wisata alam MMP seperti Kota Pontianak, Kabupaten Kubu Raya, Kota Singkawang dan Kabupaten Sambas lebih memilih berkunjung pada hari tertentu seperti akhir pekan atau hari-hari 
libur lainnya. Pengunjung dari luar kota hanya sekali - kali berkunjung ke MMP dalam 1 tahun terakhir. Faktor yang memotivasi masyarakat berkunjung ke lokasi objek wisata alam MMP selain daya tarik keindahan objek wisata MMP, adalah dikarenakan waktu atau jarak yang ditempuh dari daerah asal pengunjung ke lokasi objek wisata MMP dekat dengan pusat kota Mempawah sehingga dari segi biaya masih rerlatif murah.

Rata-rata waktu tempuh perjalanan pengunjung menuju objek wisata alam MMP dengan menggunakan kendaraan sepeda motor atau mobil seperti pada Tabel 6.

Tabel 6. Waktu Perjalanan ke Objek Wisata Alam MMP (Travel Time to Natural Tourism Objects MMP)

\begin{tabular}{llllc}
\hline No & Kategori Daya Tarik & $\begin{array}{l}\text { Frekuensi } \\
\text { (Orang) }\end{array}$ & $\begin{array}{l}\text { Persentase } \\
\mathbf{( \% )}\end{array}$ & Keterangan \\
\hline 1 & Jauh & 19 & 42.20 & $\geq 90$ menit \\
2 & Sedang & 2 & 4,40 & $70-<89$ menit \\
3 & Dekat & 24 & 53,30 & $<70$ menit \\
\hline & Total & 45 & 100,0 & \\
\hline
\end{tabular}

Sumber : Hasil analisa data primer, 2018

Berdasarkan hasil pengamatan sebagaimana Tabel 6 di atas, diketahui rata-rata waktu tempuh pengunjung ke objek wisata alam MMP antara kurang dari 70 menit (termasuk kategori dekat).

Berdasarkan pengamatan persepsi pengunjung terhadap daya tarik objek wisata alam MMP bahwa 64,44 \% pengunjung menyatakan objek wisata alam MMP cukup menarik. Daya tarik tersebut terutama mengenai keindahan alam dimana pengunjung selain dapat menikmati panorama alam vegetasi mangrove, juga panorama alam laut serta pulau yakni pulau Penibung. Presepsi pengunjung terhadap daya tarik objek wisata alam MMP dapat dilihat pada tabel 7

Tabel 7. Persepsi Responden Terhadap Daya Tarik Objek Wisata Alam MMP (Respondent's Perception of Attraction Nature Tourism MMP)

\begin{tabular}{llll}
\hline No & Kategori Daya Tarik & $\begin{array}{l}\text { Frekuensi } \\
\text { (Orang) }\end{array}$ & $\begin{array}{l}\text { Persentase } \\
(\%)\end{array}$ \\
\hline 1 & Menarik & 14 & 31,12 \\
2 & Cukup menarik & 29 & 64,44 \\
3 & Tidak menarik & 2 & 4,44 \\
\hline & Total & 45 & 100 \\
\hline
\end{tabular}

Sumber : Hasil Analisis Data Primer, 2018

Uji Asumsi Dasar

Uji Normalitas Data

Uji normalitas digunakan untuk mengetahui suatu sampel berasal dari populasi yang berdistribusi normal atau tidak. Uji normalitas dilakukan dengan melihat rasio Unstarndardized Risidual dari Skewness dan rasio Unstarndardized Risidual dari Kurtosis. Uji normalitas terhadap 45 responden 
penelitian dengan 1 (satu) variabel dependen dan 4 (empat) variabel indepenen diperoleh hasil bahwa data berdistribusi normal dengan hasil uji : $1,96<-0,157<1,96$.

\section{Uji Asumsi Klasik}

Uji Multikolinearitas data dengan melihat nilai Inflation Factor (VIF) dengan ketentuan jika nilai VIF $>5$, maka variabel tersebut mempunyai persoalan multikolinearitas. Hasil menunjukkan tidak ditemukan adanya masalah multikolinearitas dengan VIF $<$ 5. Uji Autokolerasi, model regresi hasil uji autokolerasi dengan uji DurwinWatson (uji DW). Hasil menunjukkan tidak ada autokorelasi. Uji
Heteroskedastitas, apabila nilai signifikan kurang dari 0,05 maka pada model regresi terjadi masalah Heteroskedastistas (Priyanto, 2010). Hasil Uji Heteroskedastitas menunjukkan model regresi tidak ditemukan adanya masalah heteroskesdastisitas.

Guna mengetahui pengaruh variabel bebas terhadap variabel terikat maka dilakukan uji regresi linear berganda yang terdiri atas 1 (satu) variabel terikat dan 4 (empat) variabel bebas, dengan metode Ordinary Least Square (OLS), Hasil uji regresi linear berganda seperti pada Tabel 8.

Tabel 8. Hasil Uji Regresi Linear Berganda Pengaruh Variabel Bebas Terhadap Variabel Terikat (Multiple Linear Regression Test Results Effect of Independent Variables on Bound Variables)

\begin{tabular}{|c|c|c|c|c|c|}
\hline \multirow[t]{2}{*}{ Variabel } & \multicolumn{2}{|c|}{$\begin{array}{l}\text { Unstandardized } \\
\text { Coefficients }\end{array}$} & \multirow{2}{*}{$\begin{array}{l}\text { Standardized } \\
\text { Coefficients } \\
\text { Beta }\end{array}$} & \multirow[t]{2}{*}{$\mathbf{t}$} & \multirow[t]{2}{*}{ Sig } \\
\hline & B & Std. Error & & & \\
\hline (Constant) & 3,997 & 1,882 & & 2,124 & 0,040 \\
\hline Ln $X_{1}$ (Daya Tarik) & 0,974 & 0,357 & 0,356 & 2,729 & 0,009 \\
\hline Ln $X_{2}$ (Trivel Cost) & $-0,142$ & 0,185 & $-0,112$ & $-0,765$ & 0,449 \\
\hline Ln $X_{3}$ (Waktu/Jarak) & $-0,160$ & 0,109 & $-0,217$ & $-1,465$ & 0,151 \\
\hline Ln $\mathrm{X}_{4}$ (Pendapatan) &,- 0145 & 0,065 & $-0,320$ & $-2,233$ & 0,031 \\
\hline
\end{tabular}

Sumber : Hasil analisa Data Primer, 2018

Berdasarkan Tabel 8 maka diperoleh formulasi persamaan regresi linear berganda sebagai berikut : $\mathrm{Y}^{\prime}=3,997+$ $0,974 X_{1}-0,142 X_{2}-0,160 X_{3}-0,145$ $\mathrm{X}$

Keterangan:

$\mathrm{Y}^{\prime}=$ Variabel dependen (nilai yang diprediksikan)

$\mathrm{X}_{1}$ dan $\mathrm{X}_{2}=$ Variabel independen
$\mathrm{A}=$ Konstanta (nilai $\mathrm{Y}^{\prime}$ apabila $\mathrm{X}_{1}$, $\mathrm{X}_{2} \ldots . . \mathrm{X}_{\mathrm{n}}=0$ )

$\mathrm{B}=$ Koefisien regresi (nilai peningkatan ataupun penurunan)

Hasil analisis determinasi pada Tabel 8 diperoleh angka $\mathrm{R}$ Square sebesar 0,340 atau (34\%). Hal ini menunjukkan persentase sumbangan pengaruh variabel bebas (daya tarik, travel cost, waktu, dan pendapatan) 
terhadap variabel terikat (permintaan konsumen jasa lingkungan wisata alam MMP) sebesar $34 \%$, sedangkan sisanya sebesar $66 \%$ dipengaruhi oleh variabel lain yang tidak dimasukan dalam model penelitian ini.

Nilai koefisien korelasi constant sebesar 3,997, artinya jika setiap variabel bebas nilainya 0 (nol), maka permintaan konsumen jasa lingkungan wisata alam MMP nilai adalah 3,997. Hasil uji koefisien regresi secara bersama diperoleh nilai $\mathrm{F}$ hitung sebesar 5,143, dan nilai siq $0,002<0,005$, hal ini berarti variabel bebas (daya tarik, biaya perjalanan, waktu dan pendapatan) secara bersama-sama berpengaruh signifikan terhadap permintaan konsumen jasa lingkungan wisata alam MMP.

Hasil uji secara parsial (uji t) yakni pengaruh variabel bebas terhadap variabel terikat (Permintaan konsumen jasa lingungan wisata alam MMP ) sebagai berikut :

Pengaruh Daya Tarik Objek Wisata Alam MMP Terhadap Permintaan Konsumen Jasa Lingkungan Wisata Alam MMP.

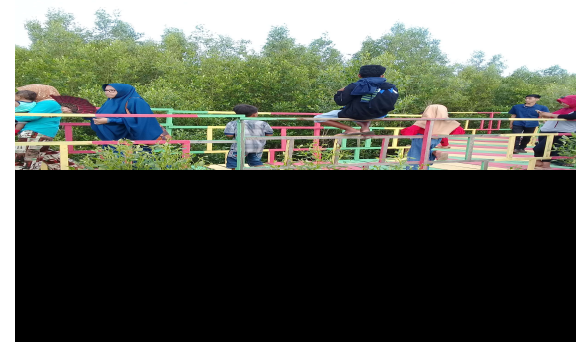

Gambar 1.

Panorama Alam Vegetasi

Hadiwijoyo (2012) menyatakan bahwa objek dan daya tarik wisata adalah
Nilai $\mathrm{t}$ hitung daya tarik positif 2,729 dan nilai sig $0,009<0,05$, dengan nilai koefisien regresi positif sebesar $(0,974)$, yang berarti variabel daya tarik objek wisata alam MMP berpengaruh positif dan signifikan terhadap permintaan konsumen jasa lingkungan wisata alam MMP. Nilai koefisien korelasi positif $(0,974)$ artinya jika daya tarik objek wisata alam MMP naik $1 \%$, maka permintaan jasa lingkungan wisata alam MMP akan meningkat sebesar 0,974 \%, dengan asumsi variabel bebas lain nilainya tetap. Model regresi tidak ditemukan adanya masalah heteroskesdastisitas.

Hasil penilaian persepsi masyarakat terhadap daya tarik objek wisata alam MMP menunjukkan 64,44 \% cukup menarik. Pengunjung menikmati keindahan-keindahan alam panorama vegetasi dan pemandangan Pulau Penibung yang dapat dilihat secara langsung. Daya tarik suatu objek wisata sangat berpengaruh terhadap minat pengunjung untuk berkunjung ke objek wisata. Salah satu bentuk daya tarik objek wisata alam MMP, dapat dilihat pada gambar 1 dan 2 .

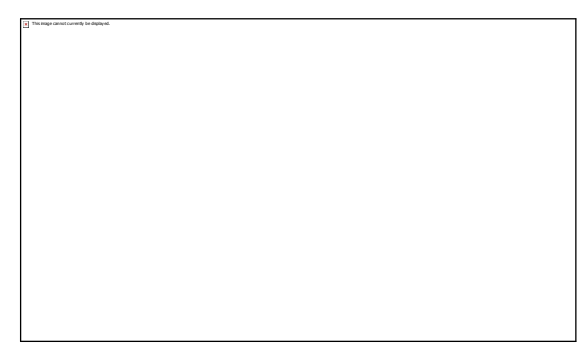

Gambar 2.

Jalan Melihat Fanorama Alam Laut dan Pulau Penibung

suatu bentukkan dan fasilitas yang berhubungan, yang dapat menarik minat 
wisatawan untuk datang ke suatu daerah atau tempat tertentu.

Pengaruh Travel Cost ke Objek Wisata MMP Terhadap Permintaan Konsumen jasa lingkungan wisata Alam MMP.

Nilai t hitung Travel Cost sebesar negatif $(-0,765)$ dan nilai sig $0,449>0,05$, dengan nilai koefisien regresi negatif sebesar $(-0,142)$. Hal ini berarti bahwa variabel Travel Cost ke Objek Wisata Alam MMP berpengaruh negatif tidak signifikan terhadap Permintaan Konsumen Jasa Lingkungan Wisata Alam MMP. Nilai koefisien korelasi negatif (- 0,142), artinya jika Travel Cost ke objek wisata alam MMP naik $1 \%$, maka permintaan jasa lingkungan wisata alam MMP akan turun sebesar $0,142 \%$, dengan asumsi variavel bebas lain nilainya tetap. Hasil pengamatan di lapangan menunjukkan biaya perjalanan (travel cost) yang dikeluarkan oleh pengunjung tergolong rendah antara $\mathrm{Rp}$ 10.000 - > Rp 64.000. Persentase biaya untuk penginapan tergolong kecil atau hampir tidak ada karena pada umumnya pengunjung hanya berwisata selama satu hari dan tidak menginap di objek ekowisata MMP. Pengunjung tidak mengeluarkan biaya tambahan seperti biaya penginapan karena sebagaian besar pengunjung merupakan masyarakat lokal sehingga pengunjung tidak akan menginap ke objek wisata tersebut. Kompenen terbesar biaya perjalanan adalah biaya transportasi, sedangkan biaya transportasi sangat dipengaruhi oleh waktu atau jarak yang diperlukan ke lokasi objek wisata, sehingga jarak sangat menentukan pemilihan tempat berwisata bagi pengunjung. Hal ini sesuai pendapatan yang dikemukakan oleh Becker et al. (2005) jarak merupakan sesuatu yang sangat berpengaruh terhadap pemilihan tempat wisata.

Pengaruh Waktu ke Objek Wisata MMP Terhadap Permintaan Konsumen jasa lingkungan wisata Alam MMP.

Nilai t hitung waktu atau jarak yang ditempuh dari derah asal ke objek wisata alam MMP sebesar negatif $(-1,465)$ dan nilai sig $0,151>0,05$, dengan nilai koefisien regresi negatif sebesar $(-0,160)$. Hal ini berarti bahwa variabel waktu ke objek wisata alam MMP berpengaruh negatif tidak signifikan terhadap permintaan konsumen jasa lingkungan wisata alam MMP. Nilai koefisien korelasi negatif $(-0,160)$, artinya jika waktu ke objek wisata alam MMP bertambah $1 \%$, maka permintaan jasa lingkungan wisata alam MMP akan turun sebesar 0,160\%, dengan asumsi variavel bebas lain nilainya tetap. Hal tersebut membuktikan permintaan konsumen semakin meningkat jika waktu (jarak) tempuh dari tempat tinggal dekat dengan objek wisata MMP. Jarak tempuh yang dekat menjadikan pengunjung lebih mudah untuk datang sehingga dalam hal ini pengujung tidak perlu mengeluarkan banyak biaya termasuk biaya transportasi yang besar dan biaya penginapan khususnya. Hal ini sejalan dengan teori Intosh (1995) dalam Khasani (2014) jarak objek wisata berhubungan dengan lama perjalanan objek wisata dari wilayah asal wisatawan berbeda dengan objek wisata tuan rumah. Umumnya semakin jauh jarak objek wisata, semakin besar ketidakinginan kunjungan wisatawan. Anasthacia (2014), jarak antara daerah tempat tinggal ke tempat objek wisata juga mempengaruhi permintaan 
akan kunjungan. Seseorang cenderung memilih tujuan wisata yang dekat dengan tempat tinggalnya untuk menekan biaya pengeluaran dalam berwisata.

Pengaruh Tingkat Pendapatan Pengunjung Terhadap Permintaan Konsumen Jasa Lingkungan Wisata Alam MMP

Nilai $\mathrm{t}$ hitung tingkat pendapatan pengunjung sebesar negatif $(-2,233)$ dan nilai sig $0,031<0,05$, dengan nilai koefisien regresi negatif sebesar $(-0,145)$. Hal ini berarti bahwa variabel Tingkat Pendapatan Pengunjung berpengaruh negatif dan signifikan terhadap Permintaan Konsumen Jasa Lingkungan Wisata Alam MMP. Nilai koefisien korelasi negatif (0,145), artinya jika tingkat pendapatan pengunjung naik $1 \%$, maka permintaan jasa lingkungan wisata alam MMP akan menurun sebesar $0,145 \%$, dengan asumsi variabel bebas lain nilainya tetap.

Berdasarkan hasil pengamatan tingkat pendapatan pengunjung (responden) yang berkunjung ke objek wisata alam MMP sebagian besar $(51,1 \%)$ rata-rata tingkat pendapatan kurang dari Rp 1.700 .000 per bulan. Pengunjung yang berkunjung ke objek wisata alam MMP adalah kelompok anak muda terdiri pelajar dan mahasiswa yang pendapatan umumnya berasal dari uang saku harian, atau pengunjungnya merupakan masyarakat golongan menengah. Sukirno (1994) dalam Gitapati (2012) menyatakan bahwa perubahan dalam pendapatan akan menimbulkan perubahan permintaan suatu produk. Semakin tinggi pendapatan sesorang, maka perjalanan wisata dianggap bukan suatu hal yang mahal.

\section{KESIMPULAN}

1. Permintaan konsumen objek wisata Mempawah Mangrove Park Kabupaten Mempawah masih tergolong sedang dengan tingkat kunjungan responden rata-rata 3 (tiga) kali dalam setahun, dan sebagian besar 48,89\% berasal dari pengunjung lokal (Kabupaten Mempawah) sekitarnya.

2. Terdapat hubungan positif dan signifikan antara daya tarik objek wisata alam MMP terhadap permintaan konsumen jasa lingkungan wisata alam MMP.

3. Terdapat hubungan negatif dan tidak signifikan antara biaya perjalanan objek wisata alam MMP terhadap permintaan konsumen jasa lingkungan wisata alam MMP.

4. Terdapat hubungan negatif dan tidak signifikan antara jarak (waktu) ke objek wisata alam MMP terhadap permintaan konsumen jasa lingkungan wisata alam MMP.

5. Terdapat hubungan negatif dan signifikan antara tingkat pendapatan pengunjung objek wisata alam MMP terhadap permintaan konsumen jasa lingkungan wisata alam MMP.

\section{SARAN}

Guna meningkatkan permintaan konsumen terhadap wisata alam MMP perlu ditingkatkan unsur utama daya tarik seperti keanekaragaman vegetasi mangrove di objek wisata alam MMP tidak hanya jenis api-api (Avicenia sp) akan tetapi jenis vegetasi mangrove lain, menambah variasi kegiatan wisata alam seperti tempat bermian anak-anak atau berwisata ke pulau Penibung, menambah unsur penunjang 
daya tarik lainnya yang menarik masih dalam ketegori kurang. Serta untuk penelitian selanjutnya sebaiknya penelitian dilakukan pada hari-hari biasa selain harihari libur.

\section{DAFTAR PUSTAKA}

Anasthacia $\mathrm{N}$ dan Purwanti EY. 2014. Analisis Permintaan Wisatawan Nusantara Objek Wisata Taman Nasional Karimunjawa Kabupaten Jepara. Undergraduate Thesis, Fakultas Ekonomika Dan Bisnis. http://eprints.undip.ac.id/43360/.

Diakses 09 Desember 2018.

Ariyanto. 2005. Ekonomi Pariwista. Jakarta.

Hhtp://www.geiocities.com. Diakses, 20 Februari 2018.

Becker N, Inbar M, Bahat O, Choresh Y, Ben-Noon G, \&Yaffe, O. 2005. Estimating the Economic Value of Viewing Griffon Vultures Gyps fulvus: a Travel Cost Model Study at Gamla Nature Reserve, Israel. Oryx, 39 (4), 429-434.

Gitapati D. 2012. Analisis Kunjungan Wisatawan Objek Wisata Nglimut Kecamatan Limbangan Kabupaten Kendal. Undergraduate thesis, Fakultas Ekonomika dan Bisnis. http://eprints.undip.ac.id/ . diakses pada 12 Januari 2019.
Hadiwijoyo SS. 2012. Perencanaan Pariwisata Perdesaan Berbas is Masyarakat, Yogyakarta: Graha Ilmu.

https://journal.ugm.ac.id/jkn/articl e/view/18006. Diakses pada 10 Desember 2018.

Indra M. 2009. Pasar Pariwisata. Ciamis http://www.wisataciamis.com. Diakses 20 Maret 2018.

Khasani, Akrom M, dan Fitrie A. 2014. Analisis Faktor-Faktor Yang Mempengaruhi Kunjungan Wisatawan Di Pantai Cahaya, Weleri, Kabupaten Kendal. Undergraduate thesis, Fakultas Ekonomika dan Bisnis. Diakses 12 Januari 2019.

Priyatno D. 2010. Paham Anaalisis Statistik Data Dengan SPSS. MediaKom. Yogyakarta.

Suzana BOL, Timban J, Kaunang R, dan Ahmad F. 2011. Valuasi Ekonomi Sumerdaya Hutan Mangrove di Desa Palaes Kecamatan Likupang Barat Kabupaten Minahasa Utara. Jurnal ilmiah Sosial Ekonomi Pertanian. ASE - Volume 7 Nomor 2, Mei 2011: 29 - 38. https://www.neliti.com/publicatio ns/3454/pendapatan-usahatanikacang-tanah-di-desa-kanonangii-kecamatan-kawangkoan 